\title{
Prediction of residual feed intake for first-lactation dairy cows using orthogonal polynomial random regression
}

\author{
G. Manafiazar, ${ }^{*}$ T. McFadden, ${ }^{*}$ L. Goonewardene, ${ }^{*}$ E. Okine, ${ }^{*}$ J. Basarab,† P. Li, $\neq$ and Z. Wang ${ }^{* 1}$ \\ *Department of Agricultural, Food and Nutritional Science, University of Alberta, Edmonton, Alberta, T6G2P5, Canada \\ †Alberta Agriculture and Rural Development, Lacombe Research Centre, 6000 C \& E Trail, Lacombe, Alberta, T4L 1W1, Canada \\ ‡Department of Statistics and Actuarial Science, University of Waterloo, Waterloo, Ontario, N2L 3G1, Canada
}

\section{ABSTRACT}

Residual Feed Intake (RFI) is a measure of energy efficiency. Developing an appropriate model to predict expected energy intake while accounting for multifunctional energy requirements of metabolic body weight (MBW), empty body weight (EBW), milk production energy requirements (MPER), and their nonlinear lactation profiles, is the key to successful prediction of RFI in dairy cattle. Individual daily actual energy intake and monthly body weight of 281 first-lactation dairy cows from 1 to $305 \mathrm{~d}$ in milk were recorded at the Dairy Research and Technology Centre of the University of Alberta (Edmonton, AB, Canada); individual monthly milk yield and compositions were obtained from the Dairy Herd Improvement Program. Combinations of different orders (1-5) of fixed $(\mathrm{F})$ and random (R) factors were fitted using Legendre polynomial regression to model the nonlinear lactation profiles of MBW, EBW, and MPER over $301 \mathrm{~d}$. The $\mathrm{F}_{5} \mathrm{R}_{3}, \mathrm{~F}_{5} \mathrm{R}_{3}$, and $\mathrm{F}_{5} \mathrm{R}_{2}$ (subscripts indicate the order fitted) models were selected, based on the combination of the log-likelihood ratio test and the Bayesian information criterion, as the best prediction equations for MBW, EBW, and MPER, respectively. The selected models were used to predict daily individual values for these traits. To consider the body reserve changes, the differences of predicted EBW between 2 consecutive days were considered as the EBW change between these days. The smoothed total 301-d actual energy intake was then linearly regressed on the total 301-d predicted traits of MBW, EBW change, and MPER to obtain the first-lactation RFI (coefficient of determination $=0.68$ ). The mean of predicted daily average lactation RFI was 0 and ranged from -6.58 to 8.64 Mcal of $\mathrm{NE}_{\mathrm{L} / \mathrm{d}}$. Fifty-one percent of the animals had an RFI value below the mean (efficient) and $49 \%$ of them had an RFI value above the mean (inefficient). These results indicate that the first-lactation RFI can

Received January 8, 2013.

Accepted August 21, 2013.

${ }^{1}$ Corresponding author: Zhiquan.Wang@ualberta.ca be predicted from its component traits with a reasonable coefficient of determination. The predicted RFI could be used in the dairy breeding program to increase profitability by selecting animals that are genetically superior in energy efficiency based on RFI, or through routinely measured traits, which are genetically correlated with RFI.

Key words: dairy cattle, feed efficiency, random regression model, residual feed intake

\section{INTRODUCTION}

Feed cost is the single-largest expense of dairy production (Vallimont et al., 2011) and has increased substantially over the last few years (Garcia, 2009). Although it is a crucial factor in the profitability of the dairy industry, little attention has been paid to improve feed efficiency through direct selection on it (Linn, 2006; Zamani et al., 2008). This is mainly due to the difficulties and costs associated with individual feed intake measurements (Kelly et al., 2010). In addition, the feed conversion ratio (FCR) and gross energy efficiency (GEE), which are the most common measures of feed utilization efficiency, have 2 main problems. The FCR is the ratio of input (e.g., feed) to output (e.g., weight gain or milk production; Crews, 2005). In the dairy industry, GEE is defined as the energy in milk divided by the total energy intake (Veerkamp and Emmans, 1995). First, the energy intake by different animals has different partial efficiencies for maintenance, lactation, and body tissue gain or loss, but FCR and GEE do not distinguish between them (Veerkamp and Emmans, 1995). Second, these measures are well known to be phenotypically and genetically correlated with measures of growth, production, and mature size (Crews, 2005). Thus, selection for improvement of FCR and GEE would result in increased growth rate, mature size, and consequently increase maintenance requirements (Crews, 2005) in an unbalanced breeding goal. To overcome the aforementioned problems of efficiency measures, an alternative measure of energy efficiency, residual feed intake (RFI), has been described. Re- 
sidual feed intake is the difference between an animal's actual energy intake (AEI) and its expected energy intake (EEI) based on animal's maintenance requirements and production level, and is phenotypically independent of production traits (Koch et al., 1963); an alternative definition of RFI is feed intake adjusted for body size and production level (milk, protein, and fat yield and changes in body fat composition). The efficient animals, which have low RFI values, consume less feed without compromising the production level.

Meat-producing animals use energy mainly for maintenance and daily weight gain during the growth period. The relationship between energy intake and production is linear in the testing period of meat-producing animals (Archer et al., 1999; Basarab et al., 2003). As a result, the evaluation methods of individual RFI for meat-producing animals during their growth period has been well studied in beef cattle, swine, and poultry using linear regression models (Archer et al., 1999; Crews, 2005). Unlike the meat-producing animals, dairy cows have multifunctional energy requirements for maintenance, growth, pregnancy, and lactation; furthermore, it is established that energy intake and energy expenditures have nonlinear profiles during the lactation period in dairy cattle, whereas their individual profiles are different among animals (Coffey et al., 2001; Bewley and Schutz, 2008). Several studies have been conducted to predict RFI in early first lactation or the whole first lactation in dairy cows, but they mainly used a linear regression model (Van Arendonk et al., 1991; Svendsen et al., 1993; Zamani et al., 2008) and limited records of individual AEI (Van Arendonk et al., 1991; Coleman et al., 2010), or used a standard table of estimated requirement values such as those of the NRC (Svendsen et al., 1993; Zamani et al., 2008). The RFI obtained from the above may not be very accurate, and worthy of further investigation (Zamani et al., 2008). In addition, based on our awareness, no previous research has used the daily actual measured feed intake data, and they collected feed intake data either weekly or monthly in their studies; therefore, their feed intake data collection methods might be too insensitive to capture the difference among animals (Vallimont et al., 2011). Moreover, most of the previous studies have not considered the nonlinear profiles of the component [metabolic BW (MBW), empty BW (EBW), and milk production energy requirements (MPER)] traits during the lactation period. The objective of this research was to develop a modeling equation to predict RFI in the first-lactation dairy cow while accounting for its multifunctional energy requirements and considering the nonlinear lactation profiles of the component traits using an orthogonal polynomial random regression technique.

\section{MATERIALS AND METHODS}

\section{Data Acquisition}

Daily individual feed intake, monthly BW, milk production, and milk composition of 281 first-lactation (1-305 DIM) dairy cows from June 2007 to October 2012, were used in the analysis. These animals were housed in a tie-stall system at the Dairy Research and Technology Center (DRTC) of the University of Alberta (Edmonton, AB, Canada). The animals received 1 of the 3 (high-, mid-, or low-energy dense ration) TMR according to their milk production level. Individual offered feed weight in the morning and refusal feed weight left on the next morning were recorded daily. Offered feed was adjusted periodically to keep the individual refusal feed around $10 \%$ of the total feed offered. Feed compositions, including moisture (\%), CP $(\%)$, and NDF (\%), were determined when the TMR ingredients changed, whereas dietary DM (\%) was measured monthly. Average DM of high-, mid-, and lowenergy dense TMR over a 5 -yr study were $52.12,51.02$, and $48.87 \%$, respectively, and their net energy density were $1.85,1.72$, and $1.65 \mathrm{Mcal} / \mathrm{kg}$ of DM, respectively. The individual milk yield and composition data were retrieved from the official DHI Program, which records milk yield and composition once every 25 to $36 \mathrm{~d}$ after calving, but no earlier than 5 DIM. Therefore, milk yield and composition data were available from 5 to 305 DIM. In addition, repeated measurements of individual $\mathrm{BW}$ and BCS of these heifers were measured at their calving and subsequently on their DHI milk sampling days during their lactation. Body condition score was assessed on a 1 to 5 scale with 0.25 intervals (Edmonson et al., 1989; NRC, 2001) by the same technician over the study period. All procedures of the study were reviewed and approved by the University of Alberta Animal Care and Use Committee.

\section{Data Editing and Trait Derivations}

Twenty cows were excluded from the analysis as they had less than 4 repeated milk yield and composition records, and 25 animals were disqualified from the data set, as they had lower than 265 AEI observations over 301 DIM. Two cows also were excluded from the data due to late age at first calving (972 and 1,175 d). In addition, 12, 48, and 487 records were removed from the BW, milk yield, and feed intake data, respectively, because they did not fall within 3 standard deviations from the population mean on the test day. The remaining $1,837,1,766$, and 67,561 repeated records of BW, milk yield, and feed intake data, respectively, from 234 cows were used in the analysis. 
Table 1. Descriptive statistics for daily value of measured and derived traits $(\mathrm{n}=234)$

\begin{tabular}{|c|c|c|c|c|c|}
\hline Trait & $\begin{array}{l}\text { No. of } \\
\text { records }\end{array}$ & Mean & $\mathrm{SE}$ & Minimum & Maximum \\
\hline \multicolumn{6}{|l|}{ Measured trait } \\
\hline BW (kg) & 1,837 & 566.83 & 53.93 & 427.00 & 754.00 \\
\hline BCS & 1,837 & 3.00 & 0.25 & 2.00 & 3.75 \\
\hline Milk (kg) & 1,766 & 30.91 & 6.16 & 12.00 & 54.00 \\
\hline Fat $(\%)$ & 1,766 & 3.58 & 0.79 & 1.24 & 7.59 \\
\hline Protein (\%) & 1,766 & 3.08 & 0.26 & 2.34 & 4.50 \\
\hline DMI (kg/d) & 67,561 & 19.47 & 4.06 & 1.66 & 38.52 \\
\hline Age at first calving (d) & 234 & 699.56 & 35.5 & 621.00 & 855.00 \\
\hline Temperature and humidity index & 65 & 43.04 & 15.47 & 13.42 & 66.78 \\
\hline \multicolumn{6}{|l|}{ Derived trait } \\
\hline Actual energy intake (Mcal of $\mathrm{NE}_{\mathrm{L}} / \mathrm{d}$ ) & 67,561 & 35.06 & 7.35 & 3.02 & 69.32 \\
\hline Metabolic BW $\left(\mathrm{kg}^{0.75}\right)$ & 1,837 & 116.35 & 7.99 & 94.26 & 143.88 \\
\hline $\begin{array}{l}\text { Milk production energy requirements (Mcal of } \\
\mathrm{NE}_{\mathrm{J}} / \mathrm{d} \text { ) }\end{array}$ & 1,766 & 21.58 & 4.39 & 7.35 & 40.93 \\
\hline Empty BW (kg) & 1,837 & 381.58 & 54.11 & 193.45 & 559.68 \\
\hline
\end{tabular}

The daily AEI, MBW, MPER, and EBW for each animal were derived from the recorded raw data using the following equations:

(1) Individual daily AEI $(\mathrm{Mcal} / \mathrm{d})=\mathrm{DMI} \times \mathrm{ED}$, where DMI $(\mathrm{kg} / \mathrm{d})$ is an individual daily DMI and ED (Mcal/ $\mathrm{kg}$ ) is the net energy density of the diet; DMI was calculated as [offered feed $(\mathrm{kg})$ - refused $(\mathrm{kg})] \times \mathrm{DM}(\%)$, where DM is the dietary DM.

(2) Metabolic BW $(\mathrm{kg})=\mathrm{BW}^{0.75}(\mathrm{~kg})(\mathrm{NRC}, 2001)$. The analysis of BW records between 5 to 305 DIM were not adjusted for fetus growth weight because the energy requirements of fetus growth is negligible in this period of pregnancy (NRC, 2001).

(3) Milk production energy requirement was considered as the energy contained in the milk produced, and it is equivalent to the sum of the heat of combustion of milk fat, protein, and lactose. Heat of combustion of milk fat, protein, and lactose were reported as 9.29, 5.71 , and 3.95, respectively. Milk lactose content is less variable and is essentially constant at $4.85 \%$ of milk (NRC, 2001). Because the DHI program does not record lactose, the MPER was calculated based on fat and protein content (NRC, 2001) and a constant value of lactose $(4.85 \% \times 3.95)$ as MPER $(\mathrm{Mcal} / \mathrm{d})=\{[0.0929$ $\times$ fat $(\%)]+[0.0547 \times \mathrm{CP}(\%)]+0.192\} \times$ milk yield .

(4) Changes in BW of dairy cows could be confounded with many factors, including water and gastrointestinal content (Bewley and Schutz, 2008), so it may not reflect true changes of tissue energy due to gut fill (NRC, 2001). Therefore, EBW was an adjusted BW for gut fill that could be representative of true changes in body tissue weight (NRC, 2001). Empty BW, on average, was considered to be $85 \%$ of live BW in dairy (NRC, 2001); however, in the current study, EBW was calculated using the equations provided by Coffey et al. (2001) to account for individual gut fill at the test day, which was a function of DMI and the energy content of the diet that each animal consumed at the test day, as $\mathrm{EBW}(\mathrm{kg})=\mathrm{BW}-\mathrm{GF}$, with $\mathrm{GF}(\mathrm{kg})=\mathrm{DMI} \times[11$ $-(7 \times \mathrm{MED} / 15)]$, where MED was the metabolizable energy density (Mcal $/ \mathrm{kg}$ ) of the diet and GF was gut fill. Descriptive statistics of both measured and derived traits are given in Table 1.

\section{Statistical Modeling}

The prediction equation of individual lactation RFI was developed in 2 steps: first, we modeled the daily nonlinear profiles of MBW, MPER, and EBW from their respective monthly measurements using an orthogonal polynomial random regression model (RRM). Second, we modeled the lactation multifunctional energy requirements of dairy cows using a multiple linear regression.

RRM Development for Individual $M B W$, MPER, and $\boldsymbol{E} \boldsymbol{B} W$. Random regression modeling is a useful technique to model the longitudinal data for each animal, and each animal could have a predicted daily value for the trait under modeling (Coffey et al., 2001). An RRM can be modeled with different regression approaches, and the Legendre polynomial random regression model was used in this study as follows:

$$
y_{i t}=F_{i t}+\sum_{m=0}^{k 1} \beta_{m} P_{m}(t)+\sum_{m=0}^{k 2} \lambda_{i m} P_{m}(t)+\varepsilon_{i t},
$$

where $y_{i t}$ is a derived trait (MBW, EBW, and MPER) for animal $i$ on day $t$, and $F_{i t}$ represents fixed effects of the population used to define contemporary groups. The fixed effects were combined month and year of measurement with ration type of 238 levels, which the animal received between 2 consecutive records; the temperature and humidity index (THI) at each test month with a total of 65 levels; and the covariate of 
animal's age at first calving deviation from the population mean (linear and quadratic). Term $\beta_{m}$ is the fixed regression coefficient for a particular contemporary group; $\lambda_{i m}$ represents random regression coefficients associated with the animal's additive genetic effects plus its permanent environmental effects; $P_{m}(t)$ is the $m$ th Legendre polynomial evaluated at time $t$; the parameters $k 1$ and $k 2$ are the order of fitted fixed (1-5) and random (1-5) polynomials regression, respectively; and $\varepsilon_{i t}$ is the residual error associated with animal $i$ at time $t$. In this study, 25 models originated from the combinations of 5 different possible orders (1-5) of fixed $(\mathbf{F})$ and random $(\mathbf{R})$ factors were fitted using Legendre polynomial regression to model the nonlinear lactation profiles of MBW, EBW, and MPER. These models were denoted as $\mathrm{F}_{k 1} \mathrm{R}_{k 2}$, where $k 1$ and $k 2$ were the order of the fitted fixed and random regression variables, respectively. For example, $\mathrm{F}_{5} \mathrm{R}_{5}$ was a model with both fixed and random variables with order of 5 . A prediction equation out of the 25 fitted models was selected as the best prediction equation for each trait based on log-likelihood ratio test (LRT) and Bayesian information criterion (BIC; Tedeschi, 2006). The LRT is a statistical test used to compare the fit of 2 models, one of which (reduced model) is a special case of the other (full model). The BIC is a criterion for model selection among a finite set of models; it is based on likelihood function and considers a penalty term for the number of parameters in the model by which a model with smaller value is better. In the current study, the model with both fifth fixed and random order $\left(\mathrm{F}_{5} \mathrm{R}_{5}\right)$ was considered as a full model, and then the LRT value was calculated between pairs of the full model and each of the other 24 reduced models as follows:

$$
\begin{aligned}
& \text { LRT }=2 \log \text {-likelihood of full model } \\
& -2 \log \text {-likelihood of reduced model. }
\end{aligned}
$$

The calculated LRT value between the full model and each of the reduced models was compared with a critical value to decide whether to reject the reduced model in favor of the full model. The critical values were determined based on degrees of freedom of change and significance level $(P<0.05)$ from chi-squared distribution. Twenty-four LRT values were calculated and compared with their corresponding critical values for each trait to find the simplified models that did not significantly differ from the $\mathrm{F}_{5} \mathrm{R}_{5}$ model. If more than 1 model was not significantly different from the full model, then the best model was determined based on the BIC among them and used to predict daily profiles for each animal from 5 to 305 DIM. The daily values were only predicted from 5 to 305 DIM for each trait (MBW, EBW, and MPER) because the first $4 \mathrm{~d}$ of milk (colostrum) production records at each lactation are not included in the DHI recording program. To consider the body reserve changes, the differences of predicted EBW between 2 consecutive days were considered to be the EBW change (EBWC) between these days. The predicted daily values for each trait of each animal $i$ were summed over $301 \mathrm{~d}$ to obtain the animal's expected first-lactation value for that trait.

Smoothing the daily actual feed intake data using predicted values from the developed prediction models is a way to reduce the error noise and capture the real pattern in the data. In the smoothing process, daily noise presumably due to error noise is reduced, and the points that are lower or higher than the adjacent points will be increased or decreased, which leads to a smooth signal. To smooth daily AEI data, the best-prediction RRM with fifth order of $\mathrm{F}$ and $\mathrm{R}$ effects was used to predict individual daily AEI. Then, predicted AEI from 5 to 305 DIM for each animal $i$ were also summed to obtain the individual's 301-d AEI $\left(\sum_{t=5}^{305} \mathrm{AEI}_{i}\right)$ and called smoothed total AEI. All of the statistical procedures were performed using PROC MIXED of SAS (SAS Institute, 2003).

Total Lactation EEI and RFI Prediction. A multiple linear regression model was used to predict the total lactation individual EEI value. The smoothed total 301-d AEI was linearly regressed on total 301-d predicted traits of MBW, MPER, and EBWC to obtain the individual's 301-d lactation EEI and RFI as follows:

$$
\begin{aligned}
& \sum_{t=5}^{305} \mathrm{AEI}_{i}= \\
& \beta_{0}+\beta_{1} \sum_{t=5}^{305} \mathrm{MBW}_{i}+\beta_{2} \sum_{t=5}^{305} \mathrm{MPER}_{i}+\beta_{3} \sum_{t=5}^{305} \mathrm{EBWC}_{i}+\sum_{t=5}^{305} \mathrm{RFI}_{i} .
\end{aligned}
$$

The 301-d first-lactation RFI for individual animal $i$ can be obtained by subtracting the total 301-d expected energy expenditures from the smoothed total 301-d AEI of the ith individual as follows:

$$
\begin{aligned}
& \sum_{t=5}^{305} \mathrm{RFI}_{i}=\sum_{t=5}^{305} \mathrm{AEI}_{i}-\sum_{t=5}^{305} \mathrm{EEI}_{i}= \\
& \sum_{t=5}^{305} \mathrm{AEI}_{i}-\left(\beta_{0}+\beta_{1} \sum_{t=5}^{305} \mathrm{MBW}_{i}+\beta_{2} \sum_{t=5}^{305} \mathrm{MPER}_{i}+\beta_{3} \sum_{t=5}^{305} \mathrm{EBWC}_{i}\right)
\end{aligned}
$$

The daily average lactation RFI for each individual over $301 \mathrm{~d}$ can be obtained by dividing the total lactation RFI by animal's days in record. 


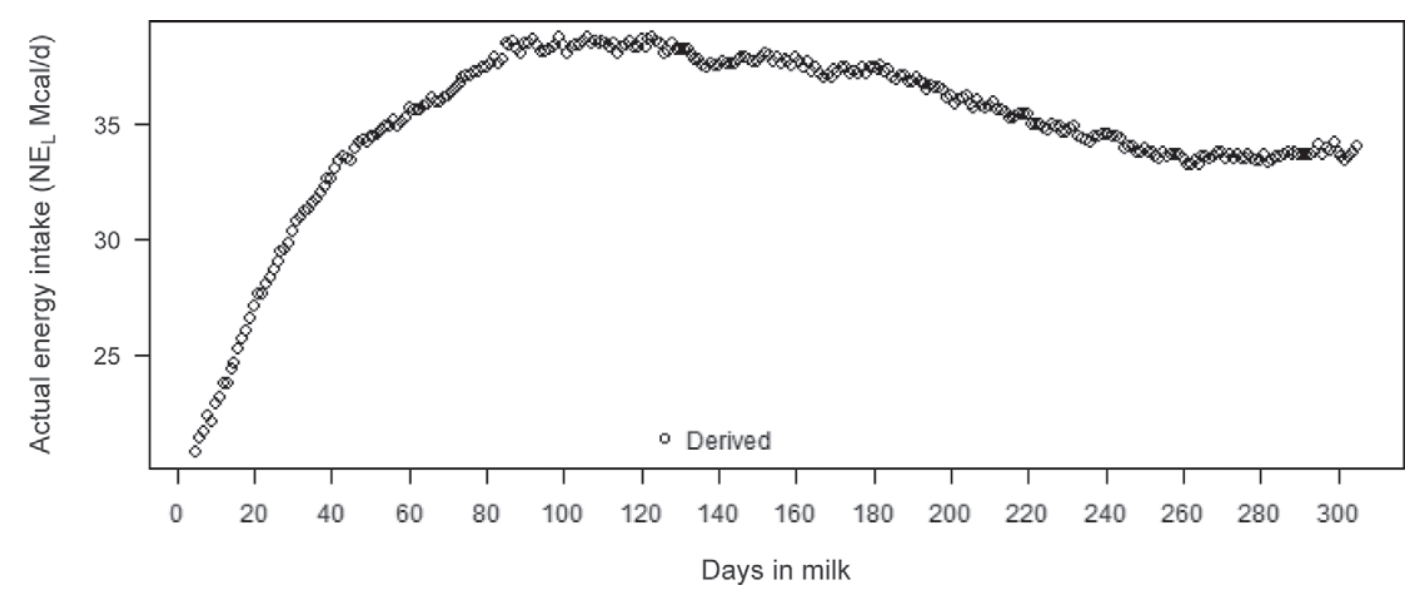

Figure 1. Average actual energy intake (Mcal of $\left.\mathrm{NE}_{\mathrm{L}} / \mathrm{d}\right)$ versus DIM.

\section{RESULTS}

Descriptive statistics of measured and derived traits are given in Table 1. The number of observations per cow for measured (BW, BCS, milk yield, and composition) and derived (MBW, EBW, and MPER) traits over $301 \mathrm{~d}$ ranged from 4 to 11 . However, the number of observations per cow for AEI was 289, on average, and ranged from 265 to 301 . The average of recorded daily AEI against DIM is shown in Figure 1; the average daily derived and predicted MPER, EBW, and MBW are shown in Figures 2, 3, and 4, respectively. The peak of AEI occurred around 100 DIM (Figure 1), whereas the peak of MPER occurred around 60 DIM (Figure 2). Animals began to lose their body reserves to support their milk production before the peak of
AEI, and the nadir point of EBW was around 60 DIM (Figure 3).

The LRT and BIC statistics for all models that were not significantly different from the full model by the LRT are presented in Table 2 for the 3 (MBW, EBW, and MPER) traits. The bold statistics indicate that the models were chosen based on BIC as the best prediction model for that trait. The models of $\mathrm{F}_{5} \mathrm{R}_{3}$, $\mathrm{F}_{5} \mathrm{R}_{3}$, and $\mathrm{F}_{5} \mathrm{R}_{2}$ were selected to predict the individual's daily values for MBW, EBW, and MPER, respectively. Scatter plots for the average daily predicted versus the average daily derived values of MPER, EBW, and MBW against DIM are shown in Figures 2, 3, and 4, respectively. It can be seen that the predicted values were matched well with their derived values for all 3 traits in their respective graphs.

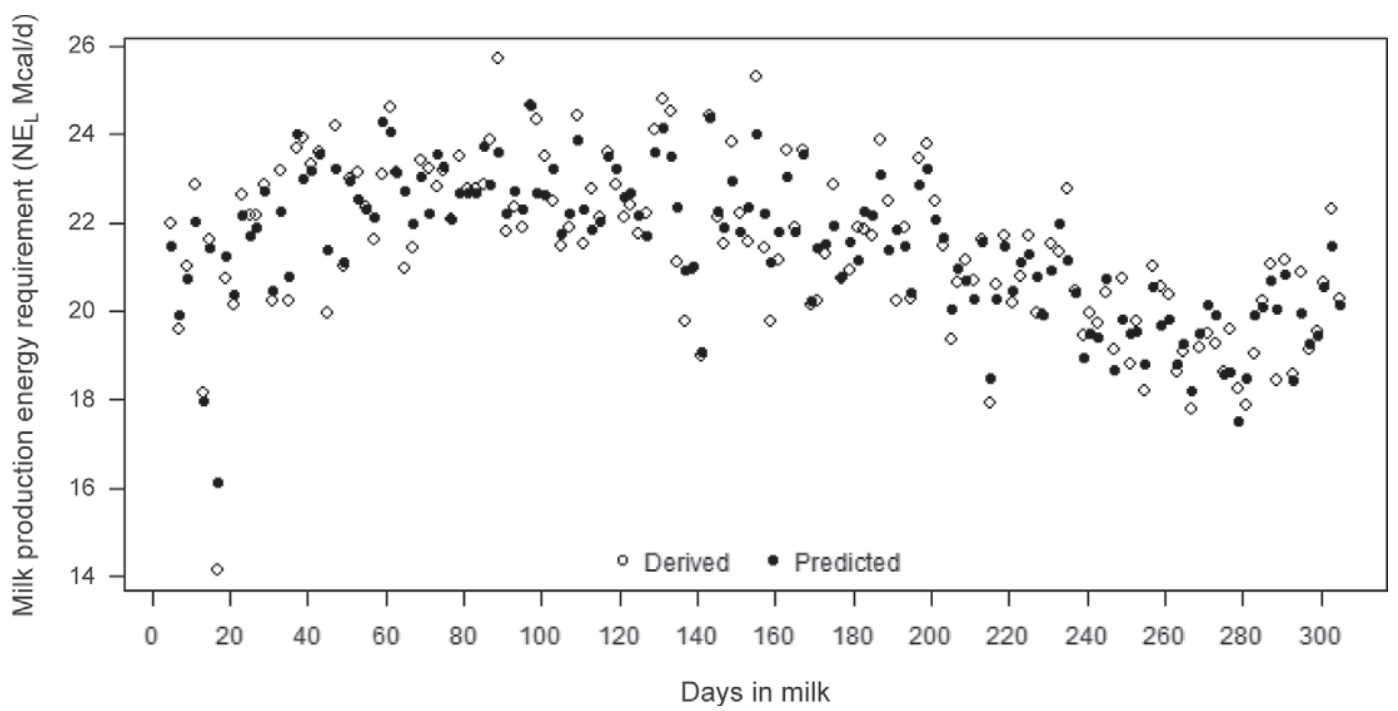

Figure 2. Average daily derived $(\diamond)$ and predicted $(\bullet)$ milk production energy requirement (Mcal of $\mathrm{NE}_{\mathrm{L}} / \mathrm{d}$ ) versus DIM. 


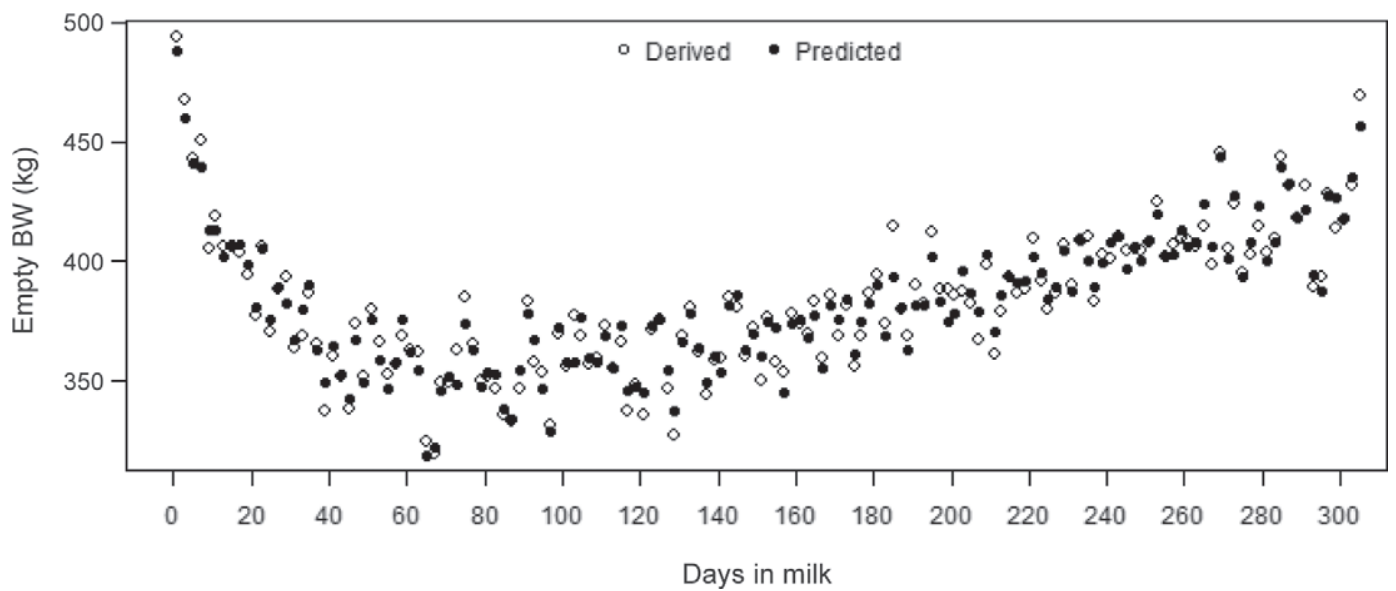

Figure 3. Average daily derived $(\diamond)$ and predicted $(\bullet)$ empty BW $(\mathrm{kg})$ versus DIM.

The developed EEI prediction equation is given below with a coefficient of determination of 0.68 :

$$
\begin{aligned}
& \sum_{t=5}^{305} \mathrm{EEI}_{i}=-2,518.61+0.22 \times \sum_{t=5}^{305} \mathrm{MBW}_{i}+0.84 \\
& \times \sum_{t=5}^{305} \mathrm{MPER}_{i}-1.51 \times \sum_{t=5}^{305} \mathrm{EBWC}_{i},
\end{aligned}
$$

and the 301-d individual lactation RFI can be predicted as follows:

$\sum_{t=5}^{305} \mathrm{RFI}_{i}=\sum_{t=5}^{305} \mathrm{AEI}_{i}-$

$\left[-2,518.61+\left(0.22 \times \sum_{t=5}^{305} \mathrm{MBW}_{i}\right)+\left(0.84 \times \sum_{t=5}^{305} \mathrm{MPER}_{i}\right)-\left(1.51 \times \sum_{t=5}^{305} \mathrm{EBWC}_{i}\right)\right]$.

The mean of predicted daily average lactation RFI was 0.0 and ranged from -6.58 to $8.64 \mathrm{Mcal}$ of $\mathrm{NE}_{\mathrm{L}} / \mathrm{d}$ (Figure 5). Fifty-one percent of the animals had an RFI value below the mean (efficient) and $49 \%$ of them had a RFI value above the mean (inefficient).

\section{DISCUSSION}

\section{Advantages of the Developed Model}

The objective of this study was to develop a prediction equation to calculate lactation RFI for dairy cows during their whole first-lactation period and to account for the animals' multifunctional energy requirements. The developed prediction model also considered the nonlinear lactation profiles of RFI component traits and used smoothed daily actual feed intake data during the whole lactation period. In this research, measured AEI data was smoothed to remove the error noise in RFI prediction equation. However, applying measured AEI data in the RFI prediction equation provided very similar results to the smoothed AEI data. The correlation between predicted RFI from measured AEI and

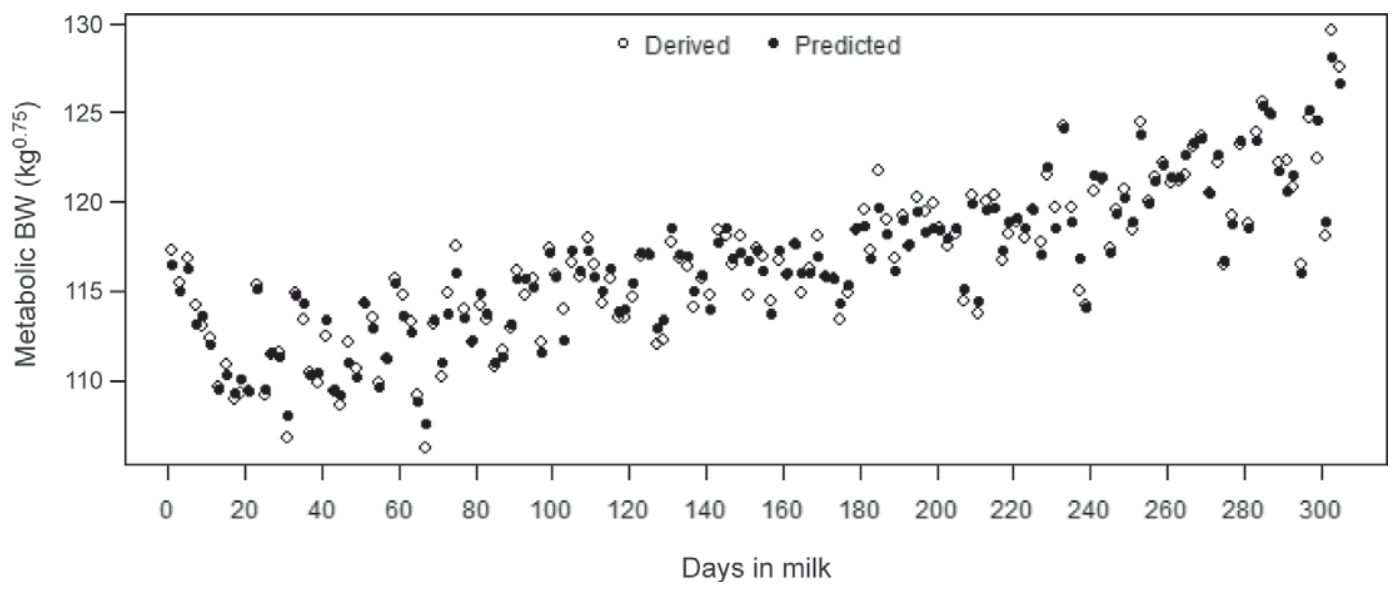

Figure 4. Average daily derived $(\diamond)$ and predicted $(\bullet)$ metabolic BW $\left(\mathrm{kg}^{0.75}\right)$ versus DIM. 


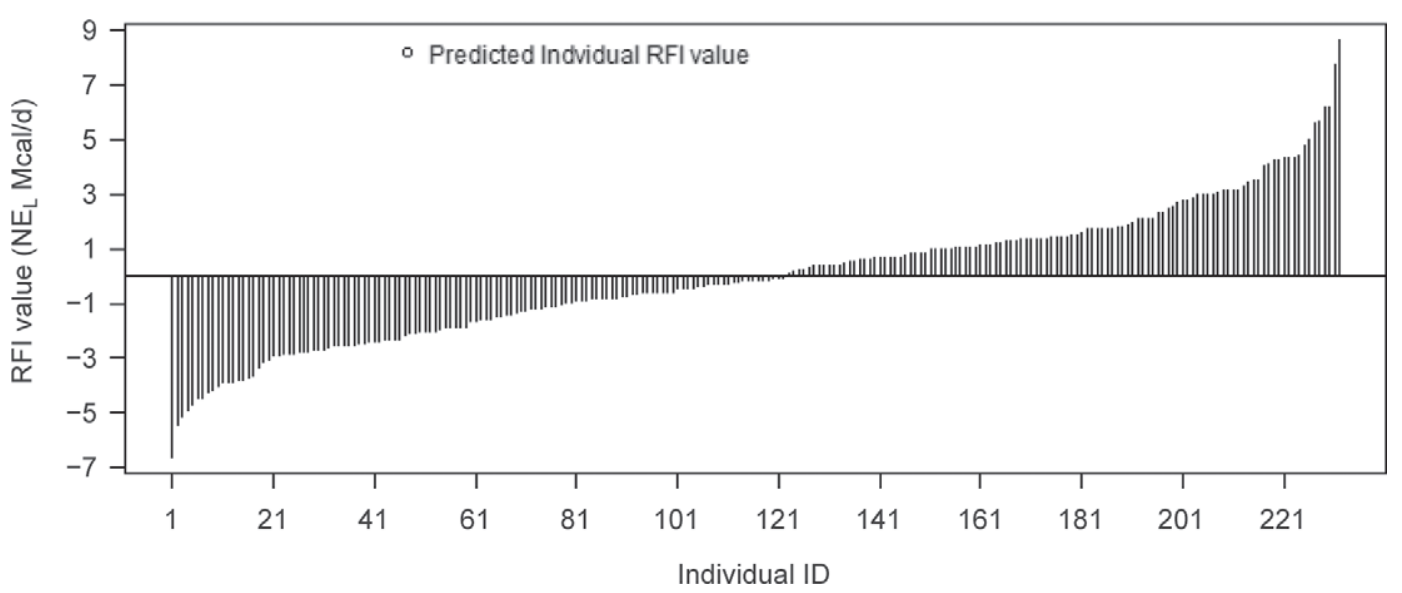

Figure 5. Average daily residual feed intake (RFI). Each bar indicates daily RFI (Mcal of $\mathrm{NE}_{\mathrm{L}} / \mathrm{d}$ ) for each dairy cow. ID = identification.

smoothed AEI was 0.96. Therefore, 289 repeated measurements of AEI over $301 \mathrm{~d}$ may be good enough to capture the real pattern of feed intake in dairy cattle, and smoothed data may be more useful to remove error noise when less-repeated data points over lactation are recorded.

Several previous RFI prediction studies (Van Arendonk et al., 1991; Svendsen et al., 1993; Zamani et al., 2008; Coleman et al., 2010; Vallimont et al., 2011) for dairy cattle in the literature are summarized in Table 3. Van Arendonk et al. (1991) predicted RFI in early lactation (105 DIM) using linear regression of average daily energy intake on average daily $\mathrm{MBW}$, average daily fat- and protein-corrected milk, and average daily weight gain. In this study, we used the actual daily feed intake records from the entire lactation to develop an RFI prediction equation for the first-lactation dairy cow (301 DIM) rather than early lactation (105 DIM). Furthermore, Van Arendonk et al. (1991) used the av- erage of BW gain over $77 \mathrm{~d}$ in the prediction model. Applying an average of BW in early lactation could give a biased result, as measuring BW around the nadir point is important to ensure accurate appraisal of BW gain or loss. It is also well established that dairy animals lose their energy reserves (BW and BCS) to support milk production in early lactation and start to regain their reserves after the energy intake peak occurs (Coffey et al., 2001; Bewley and Schutz, 2008), which is also supported by the results found in the current study (Figure 3). For example, consider a cow that had 0.15 $\mathrm{kg}$ of weight loss in the first $50 \mathrm{~d}$ in the test and 0.27 $\mathrm{kg}$ of weight gain for the rest of $27 \mathrm{~d}$ in the test (from 50 to $77 \mathrm{~d}$ in the test) in the study by Van Arendonk et al. (1991). The cow might have zero average BW gain during $77 \mathrm{~d}$ if her nadir point occurred at the $\mathrm{d} 50$. To accurately consider the body reserve changes, RFI may be predicted in a shorter time, such as weekly; then, total lactation RFI could be calculated to be the sum

Table 2. Maximum log-likelihood, log-likelihood ratio test (LRT), and Bayesian information criterion (BIC) values of different models, which were not significantly different from the full model $\left(\mathrm{F}_{5} \mathrm{R}_{5}\right)^{1}$ for metabolic BW (MBW), milk production energy requirements $(\mathrm{MPER})$, and empty $\mathrm{BW}(\mathrm{EBW})^{2}$

\begin{tabular}{|c|c|c|c|c|c|c|c|c|c|c|}
\hline \multirow{2}{*}{ Model $^{3}$} & \multirow{2}{*}{$\begin{array}{c}\text { df } \\
\text { change }\end{array}$} & \multicolumn{9}{|c|}{ Trait } \\
\hline & & \multicolumn{3}{|c|}{ MBW } & \multicolumn{3}{|c|}{ MPER } & \multicolumn{3}{|c|}{ EBW } \\
\hline $\mathrm{F}_{4} \mathrm{R}_{2}$ & 12 & - & - & - & $-4,901.5$ & 23.6 & $9,870.0$ & - & - & - \\
\hline $\mathrm{F}_{4} \mathrm{R}_{3}$ & 7 & - & - & - & $-4,899.0$ & 18.5 & $9,842.8$ & - & - & - \\
\hline $\mathrm{F}_{5} \mathrm{R}_{4}$ & 6 & $-5,414.6$ & 9.9 & $1,0924.4$ & $-4,892.9$ & 6.0 & $9,871.0$ & $-9,293.7$ & 3.5 & $7,148.8$ \\
\hline $\mathrm{F}_{5} \mathrm{R}_{5}$ & & $-5,409.6$ & & $1,0944.0$ & $-4,889.7$ & & $9,904.3$ & $-9,289.8$ & & $7,180.3$ \\
\hline
\end{tabular}


of weekly predicted RFI over lactation. In this research, RFI component traits, including EBWC, were summed over the lactation period to calculate total lactation RFI ( $\left.\mathrm{RFI}_{\text {Lactation }}\right)$. Moreover, we calculated individual weekly RFI, and then the total individual lactation RFI was calculated by summing up the weekly RFI $\left(\mathrm{RFI}_{\text {Weekly }}\right)$ over lactation. The 2 methods yielded very similar results: the means (SD) of $\mathrm{RFI}_{\text {Lactation }}$ and $\mathrm{RFI}_{\text {Weekly }}$ were 0.0 (2.42) and 0.0 (2.46), respectively, and RFI obtained from these 2 methods had a correlation of 0.97 . Summing up the RFI component traits method is much easier computationally and more applicable compared with the weekly approach.

Coleman et al. (2010) developed an RFI prediction equation for first-lactation cows from 16 to 288 DIM in a pasture-based system (Table 3). They predicted RFI by regression of estimated daily DMI on predicted daily energy expenditures (fat yield, protein yield, lactose yield, MBW, BW change, and BCS) over 272 d. On one hand, Coleman et al. (2010) estimated individual DMI by the $n$-alkane technique on 6 occasions from 16 to 288 DIM. The estimated observations were then used to develop a prediction equation based on a cubic spline regression method to obtain an estimated daily DMI for each animal over $272 \mathrm{~d}$. On the other hand, they predicted DMI based on animal energy expenditures (fat yield, protein yield, lactose yield, MBW, BW change, and BCS). Then, they considered individual
RFI as the difference between daily estimated DMI from the cubic spline regression data, with predicted DMI based on animal energy expenditures. However, RFI prediction is the difference between daily actual DM or energy intake, with predicted DM or energy intake based on animal energy expenditures. Therefore, the main difference between our study and that of Coleman et al. (2010) was that they used estimated daily DMI in their study, whereas we used smoothed actual daily DMI measurements in the RFI prediction to subtract predicted DMI based on animal energy expenditures. Wang et al. (2006) reported that accurate RFI test results required at least 63-d observations of actual daily DMI in a 90-d period of a feed lot trial of RFI prediction for beef cattle. Although their results may not directly be applicable to dairy cattle, at least their results indicate that an adequate number of DMI data measurements are required to have an accurate RFI prediction, even with linear prediction in beef cattle. Coleman et al. (2010) had a lower number of daily actual DMI data than our study (6 vs. 289), so they might suffer from loss of prediction accuracy.

Two other studies (Svendsen et al., 1993; Zamani et al., 2008) predicted RFI for the first 2 trimesters and the entire first-lactation period (Table 3), respectively. Both of these research teams used the table values of the standard NRC nutrient requirements to estimate energy expenditures instead of using actual individual

Table 3. Summary of available residual feed intake (RFI) prediction report in the literature

\begin{tabular}{|c|c|c|c|c|c|c|}
\hline Item $^{1}$ & Current study & $\begin{array}{l}\text { Vallimont et } \\
\text { al. }(2011)\end{array}$ & $\begin{array}{l}\text { Coleman et } \\
\text { al. }(2010)\end{array}$ & $\begin{array}{l}\text { Zamani et } \\
\text { al. (2008) }\end{array}$ & $\begin{array}{l}\text { Svendsen et } \\
\text { al. (1993) }\end{array}$ & $\begin{array}{l}\text { Van Arendonk et } \\
\text { al. (1991) }\end{array}$ \\
\hline Breed & Holstein & Holstein & Holstein & Holstein & Dual & Holstein \\
\hline Raised system & Tie-stall & Tie-stall & Pasture & Tie-stall & Tie-stall & Tie-stall \\
\hline $\mathrm{n}$ & 281 & 970 & 265 & 906 & 353 & 360 \\
\hline Test duration & 300 & 305 & 267 & 365 & 168 & 105 \\
\hline Regression approach to model energy sink profiles & $\mathrm{NL}^{2}$ & $\mathrm{NL}$ & NL & $\mathrm{NP}^{3}$ & NP & $\mathrm{L}^{4}$ \\
\hline $\begin{array}{l}\text { Regression approach to model relationship } \\
\text { between energy intake and sinks }\end{array}$ & $\mathrm{L} ; \mathrm{NL}$ & $\mathrm{L}$ & $\mathrm{L}$ & $\mathrm{L}$ & $\mathrm{L}$ & $\mathrm{L}$ \\
\hline Recorded actual feed intake/cow & 289 & 6 & 6 & 52 & $\mathrm{NP}$ & 44 \\
\hline $\mathrm{R}^{2}$ of RFI prediction equation & 0.68 & $\mathrm{NP}$ & $\mathrm{NP}$ & NP & NP & NP \\
\hline \multicolumn{7}{|l|}{$\begin{array}{l}\text { Components included in expected } \\
\text { energy intake equation }\end{array}$} \\
\hline MBW & $* 5$ & - & $*$ & $*$ & $*$ & $*$ \\
\hline MYC & $*$ & $*$ & $*$ & $*$ & $*$ & $*$ \\
\hline EBWC & $*$ & - & - & - & - & - \\
\hline BW & - & $*$ & - & - & - & - \\
\hline $\mathrm{BCS}$ & - & $*$ & $*$ & $*$ & - & - \\
\hline $\mathrm{ADG}$ & - & - & $*$ & $*$ & $*$ & $*$ \\
\hline RFI & Mcal of $\mathrm{NE}_{\mathrm{L}} / \mathrm{d}$ & & $\mathrm{kg}$ of $\mathrm{DM} / \mathrm{d}$ & $\mathrm{Mcal} / \mathrm{d}$ & & MJ of $\mathrm{ME} / \mathrm{kg}$ \\
\hline Mean & 0.00 & NP & 0.03 & 4.64 & NP & 64.2 \\
\hline Minimum & -6.58 & NP & -0.38 & -9.43 & NP & 42.1 \\
\hline Maximum & 8.64 & $\mathrm{NP}$ & 0.44 & 18.6 & NP & 86.4 \\
\hline
\end{tabular}

${ }^{1} \mathrm{MBW}=$ metabolic BW; MYC = milk yield and components; EBWC = empty BW change.

${ }^{2} \mathrm{NL}=$ nonlinear.

${ }^{3} \mathrm{NP}=$ not provided.

${ }^{4} \mathrm{~L}=$ linear.

${ }^{5}$ Components included in the expected energy intake equation are indicated by an asterisk $\left({ }^{*}\right)$. 
feed intake measurements. Moreover, the standard requirements tables such as those of the NRC were prepared based on population averages and were not applicable to identify an efficient individual. In the current study, both group mean efficiency (the fixed effects) and the individual deviation of efficiency (the random effects) from the group mean were modeled and the latter allowed us to identify efficient animals within the group.

\section{Model Development and Selection}

Twenty-five Legendre polynomial RRM were fitted for each of the energy expenditure components (MBW, EBW, and MPER), and then LRT along with the BIC were used to select the best prediction equation for the energy expenditures. Random regression modeling is a useful technique for analyzing longitudinal traits, such as feed intake, milk production, and BCS (Schaeffer, 2004). It is a flexible model that allows regression coefficients to be different among animals, giving each animal a specific model (Schaeffer and Dekkers, 1994). In an RRM, an average curve of a trait for all animals in a particular group is fitted as a fixed regression, and deviation of each animal from this average curve is modeled using random Legendre polynomials (Coffey et al., 2001; Schaeffer, 2004). Legendre polynomials have advantages of having good convergence and lower correlations between coefficients, as the coefficients are orthogonal compared with an ordinary polynomial (Coffey et al., 2001; Schaeffer, 2004). The common statistical criteria such as mean square of error, or coefficient of determination were not useful for our model selection because the numbers of parameters to be estimated were different for all possible combinations of the RRM. Therefore, we first used LRT to test the proficiency of reduced models compared with the full model and then BIC was used to select the best model among the models that were as efficient as the full model.

The preliminary results of the tested fixed and random regression orders of 1 to 10 for the traits showed that most of the orders greater than 5 had a convergence problem. Therefore, 5 possible orders (1-5) of $\mathrm{F}$ and $\mathrm{R}$ Legendre polynomial regression models were tested to model the daily nonlinear lactation profiles of MBW, EBW, and MPER with time. For the 3 derived traits, a fixed regression of order $5\left(\mathrm{~F}_{5}\right)$ was selected, whereas random regression of order $3\left(\mathrm{R}_{3}\right), 3\left(\mathrm{R}_{3}\right)$, and $2\left(\mathrm{R}_{2}\right)$ were selected for MBW, EBW, and MPER, respectively, and were used to predict their respective daily values for each animal. Several reports used Legendre polynomial RRM technique to model BW, energy balance, and milk yield within the first-lactation period (Coffey et al., 2001; Banos et al., 2005; Liu et al., 2006). They considered a fixed regression order of 5 to model average records across all animals for the tested traits. Random orders of 5 and more were suggested to be used for modeling of energy balance, which was a derived trait from BW and BCS (Banos et al., 2005). It is noted that the random regression model consists of fixed and random parts. The random part of the model could be partitioned into different parts, including animal additive and permanent environmental effects (Coffey et al., 2001). If the random part did not partition, it would be a combined effect of animal additive and permanent environmental effects. Currently, a random order of 4 is being used for both additive and permanent effects in Canada for modeling of milk yield within the first lactation (Interbull, 2009). However, Liu et al. (2006) tested Legendre polynomial random orders of 3 to 8 to select the best order of fit for milk yield using some statistical criteria, including LRT and BIC. They also compared the selected model with the currently used model (order of 4 for both additive and permanent random effects) in Canada and found that the random orders of 5 and 7 were the best orders for additive and permanent random effects, respectively. Therefore, they concluded that the model used in the Canadian Holstein dairy evaluation was not the best, based on a single criterion, but was optimal when considering all criteria including LRT and BIC. However, in the current research, pedigree information was not included in the analysis, as we were interested in predicting phenotypic RFI. Therefore, the animal random effect was a combination of animal additive and permanent effects. Overall, the selected models in the current study were the best models that fitted the traits (Figures 2, 3, and 4), and they were in line with comparable results in the literature.

\section{EEI Equation and RFI Calculation}

The linear and quadratic relationships between smoothed total AEI and total MBW, EBWC, and MPER were examined. The linear RFI prediction equation had a coefficient of determination of 0.68 . The quadratic multiple regression adds just $2 \%$ to the coefficient of determination in the linear model, and none of the quadratic terms in the nonlinear prediction equation were statistically significant $(P>0.34)$. The coefficient of determination determines the percentage of the variation of the dependent variable (AEI) that is explained by independent variables (MBW, EBWC, and MPER). It is a good indicator for comparing the different RFI prediction modeling approaches. Ideally, we should compare the coefficient of determination of our prediction equation with other available RFI 
predictions from the literature. However, based on our awareness of published results, none of them provided a coefficient of determination for their RFI prediction equations (Table 3). Therefore, we could not compare the coefficient of determination directly with the prediction equations in the previous works in the literature.

Individual AEI and EEI, which is predicted based on animal maintenance and production requirements, are necessary to calculate individual RFI. The RFI calculation method has been well established in beef cattle during the growth period. Generally, daily DMI and biweekly BW are recorded over $90 \mathrm{~d}$ in beef cattle during their growth period. Then, linear regression of measured weight over time is used to model the growth curve for each animal and predict its MBW and ADG (Basarab et al., 2003; Wang et al., 2006; Kelly et al., 2010). Basarab et al. (2003) used linear regression to model the growth curve of beef steers to predict the mid-test BW and ADG of animals during the feedlot test period and reported that all animals had a growth curve with a coefficient of determination of more than $95 \%$, indicating that the growth during this phase was linear and the selection of a linear regression model was an appropriate approach. Consequently, expected DMI was calculated from linear regression of actual daily DMI on estimated MBW and ADG. As a result, the coefficient of determination of RFI prediction equation ranged from 0.72 to 0.82 in beef cattle (Basarab et al., 2003, 2007). However, energy requirements of dairy cows are complicated and they need energy to produce milk, grow, conceive, and bring their calves to term while maintaining themselves as biological entities, staying healthy, and keeping up with general activities (Banos et al., 2005). In dairy cattle, the amount of energy intake and that dispensed by an animal determines its body energy state. Almost all lactating animals tend to lose their body reserves to support lactogenesis, especially in high milk-producing cows (Coffey et al., 2001). Therefore, accounting for nonlinear lactation profiles for multifunctional energy requirements of expected individual energy intake over DIM is the key success to obtain an accurate RFI prediction for dairy cows. In the current study, the nonlinear lactation profiles of energy expenditures were accounted for by using RRM and a summation of individual daily values over the trajectory. For multiple requirements, the authors initially considered smoothed AEI as functions of total MBW, MPER, and BW over $301 \mathrm{~d}$ and accounted for $56 \%$ of variation in AEI. Including BCS in the initial model produced an equation with a coefficient of determination of about 0.58. However, after adjusting BW for gut fill and EBW, and then calculating the EBWC and replacing with BW and BCS, we provided a model that accounted for $68 \%$ of variation in AEI. The previ- ous research teams in dairy cattle did not report coefficients of determination for RFI calculation; however, the achieved coefficient of determination value for RFI prediction equation was close to the lower range of beef studies (Basarab et al., 2003, 2007). In this study, the mean of average daily lactation RFI was 0.0 (SD $=2.42 \mathrm{Mcal}$ of $\mathrm{NE}_{\mathrm{L}} / \mathrm{d} ; 1.33 \mathrm{~kg}$ of $\mathrm{DM} / \mathrm{d}$ ) and ranged from -6.58 to $8.64 \mathrm{Mcal}$ of $\mathrm{NE}_{\mathrm{L}} / \mathrm{d}(-3.59$ to $4.77 \mathrm{~kg}$ of $\mathrm{DM} / \mathrm{d})$. Other researchers also reported an average of zero for RFI in dairy (Van Arendonk et al., 1991; Coleman et al., 2010), but no standard deviation was given. The standard deviation of RFI estimation in growing beef cattle was reported as almost $0.56 \mathrm{~kg}$ of DM/d and the range of RFI values has been reported from -2.5 to $+2.2 \mathrm{~kg}$ of $\mathrm{DM} / \mathrm{d}$ (Basarab et al., 2003; Wang et al., 2006; Kelly et al., 2010), with an average of zero.

\section{CONCLUSIONS}

The $\mathrm{F}_{5} \mathrm{R}_{3}, \mathrm{~F}_{5} \mathrm{R}_{3}$, and $\mathrm{F}_{5} \mathrm{R}_{2} \mathrm{RRM}$ were selected as the best models to model the daily nonlinear profiles and to predict individual daily values of MBW, EBW, and MPER, respectively. The results indicated that the first-lactation RFI is predictable and could be used in the dairy industry to increase profitability by selecting animals that are genetically superior in energy efficiency based on the predicted RFI without compromising the production level, through indicator traits such as conformation traits, marker-assisted selection, and other genomic approaches. However, further investigations are required to develop a prediction equation to calculate RFI across the lactation. In addition, a need exists to investigate the phenotypic and genetic correlations between RFI and conformation traits, fertility, and lifetime profitability, and to investigate indicator trait(s) in an effort to ensure that the measurement of feed intake and, consequently, RFI calculation is more cost effective.

\section{ACKNOWLEDGMENTS}

The authors are greatly thankful for the experimental support from the staff at the Dairy Research and Technology Center (DRTC) of the University of Alberta (Edmonton, AB, Canada), especially Reza Khorasani, the DRTC manager, and Harold Lehman, a senior DRTC technician. The financial support from the Natural Science and Engineering Research Council of Canada (NSERC, Ottawa, ON, Canada) is also greatly appreciated.

\section{REFERENCES}

Archer, J. A., E. C. Richardson, R. M. Herd, and P. F. Arthur. 1999. Potential for selection to improve efficiency of feed use in beef cattle: A review. Aust. J. Agric. Res. 50:147-161. 
Banos, G., M. P. Coffey, and S. Brotherstone. 2005. Modeling daily energy balance of dairy cows in the first three lactations. J. Dairy Sci. 88:2226-2237.

Basarab, J. A., D. McCartney, E. K. Okine, and V. S. Baron. 2007. Relationship between progeny residual feed intake and dam productivity traits. Can. J. Anim. Sci. 87:489-502.

Basarab, J. A., M. A. Price, J. L. Aalhus, E. K. Okine, W. M. Snelling, and K. L. Lyle. 2003. Residual feed intake and body composition in young growing cattle. Can. J. Anim. Sci. 83:189-204.

Bewley, J. M., and M. M. Schutz. 2008. Review: An interdisciplinary review of body condition scoring for dairy cattle. Prof. Anim. Sci. 24:507-529.

Coffey, M. P., G. C. Emmans, and S. Brotherstone. 2001. Genetic evaluation of dairy bulls for energy balance traits using random regression. Anim. Sci. 73:29-40.

Coleman, J., D. P. Berry, K. M. Pierce, A. Brennan, and B. Horan. 2010. Dry matter intake and feed efficiency profiles of 3 genotypes of Holstein-Friesian within pasture-based systems of milk production. J. Dairy Sci. 93:4318-4331.

Crews, D. H. Jr. 2005. Genetics of efficient feed utilization and national cattle evaluation: A review. Genet. Mol. Res. 4:152-165.

Edmonson, A. J., I. J. Lean, L. D. Weaver, T. Farver, and G. Webster. 1989. A body condition scoring chart for Holstein dairy cows. J. Dairy Sci. 72:68-78.

Garcia, A. 2009. Dairy profitability 101: Milk quality and feed efficiency. Extension extra. South Dakota State University. Accessed Sep. 24, 2013. http://pubstorage.sdstate.edu/AgBio_Publications/articles/ExEx4042.pdf.

Interbull. 2009. Interbull Form GE: Description of national genetic evaluation system and trend validation for production traits. Accessed Sep. 25, 2013. https://www.pdffiller.com/en/project/11275515.htm.

Kelly, A. K., M. McGee, D. H. Jr. Crews, A. G. Fahey, A. R. Wylie, and D. A. Kenny. 2010. Effect of divergence in residual feed intake on feeding behavior, blood metabolic variables, and body composition traits in growing beef heifers. J. Anim. Sci. 88:109-123.

Koch, R. M., L. A. Swiger, D. Chambers, and K. E. Gregory. 1963. Efficiency of feed use in beef cattle. J. Anim. Sci. 22:486-494.

Linn, J. 2006. Feed efficiency: Its economic impact in lactating cows. WCDS Adv. Dairy Technol. 18:19-28.
Liu, Y. X., J. Zhang, L. R. Schaeffer, R. Q. Yang, and W. L. Zhang. 2006. Short communication: Optimal random regression models for milk production in dairy cattle. J. Dairy Sci. 89:2233-2235.

NRC. 2001. Nutrient Requirements of Dairy Cattle. 7th rev. ed. Natl. Acad. Sci., Washington, DC.

SAS Institute. 2003. SAS for Windows, User's Guide. Version 9.1.3. SAS Institute Inc., Cary, NC.

Schaeffer, L. R. 2004. Application of random regression models in animal breeding. Livest. Prod. Sci. 86:35-45.

Schaeffer, L. R., and J. C. M. Dekkers. 1994. Random regression in animal models for test-day production in dairy cattle. Pages 443446 in Proc. 5th World Congr. Genetics Appl. Livest. Prod. Vol. XVIII. Guelph, ON, Canada. Department of Animal and Poultry Science, University of Guelph, Guelph, ON, Canada.

Svendsen, M., P. Skipenes, and I. L. Mao. 1993. Genetic parameters in feed conversion complex of primiparous cows in the first two trimesters. J. Anim. Sci. 71:1721-1729.

Tedeschi, L. O. 2006. Assessment of the adequacy of mathematical models. Agric. Syst. 89:225-247.

Vallimont, J. E., C. D. Dechow, J. M. Daubert, M. W. Dekleva, J. W. Blum, C. M. Barlieb, W. Liu, G. A. Varga, A. J. Heinrichs, and C. R. Baumrucker. 2011. Short communication: Heritability of gross feed efficiency and association with yield, intake, residual intake, body weight, and body condition score in 11 commercial Pennsylvania tie stalls. J. Dairy Sci. 94:2108-2113.

Van Arendonk, J. A. M., G. J. Nieuwhof, H. Vos, and S. Korver. 1991. Genetic aspect of feed intake and efficiency in lactating dairy heifers. Livest. Prod. Sci. 29:263-275.

Veerkamp, R. F., and G. C. Emmans. 1995. Sources of genetic variation in energetic efficiency of dairy cows. Livest. Prod. Sci. 44:87-97.

Wang, Z., J. D. Nkrumah, C. Li, J. A. Basarab, L. A. Goonewardene, E. K. Okine, D. H. Crews, and S. S. Moore. 2006. Test duration for growth, feed intake, and feed efficiency in beef cattle using the GrowSafe system. J. Anim. Sci. 84:2289-2298.

Zamani, P., S. R. Miraei-Ashtiani, and H. Mohammadi. 2008. Genetic parameters of residual energy intake and its correlations with other traits in Holstein dairy cattle. Turk. J. Vet. Anim. Sci. $32: 255-261$. 